\title{
Workforce capacity to address obesity: a Western Australian cross-sectional study identifies the gap between health priority and human resources needed
}

\author{
Andrea Begley ${ }^{1 *}$ (D) and Christina Mary Pollard ${ }^{1,2}$
}

\begin{abstract}
Background: The disease burden due to poor nutrition, physical inactivity and obesity is high and increasing. An adequately sized and skilled workforce is required to respond to this issue. This study describes the public health nutrition and physical activity (NAPA) practice priorities and explores health managers and practitioner's beliefs regarding workforce capacity to deliver on these priorities.

Methods: A workforce audit was conducted including a telephone survey of all managers and a postal survey of practitioners working in the area of NAPA promotion in Western Australia in 2004. Managers gave their perspective on workforce priorities, current competencies and future needs, with a $70 \%$ response rate. Practitioners reported on public health workforce priorities, qualifications and needs, with a $56 \%$ response rate.

Results: The top practice priorities for managers were diabetes (35\%), alcohol and other drugs (33\%), and cardiovascular disease (27\%). Obesity (19\%), poor nutrition (15\%) and inadequate physical activity (10\%) were of lower priority. For nutrition, managers identified lack of staff (60.4\%), organisational and management factors (39.5\%) and insufficient financial resources (30.2\%) as the major barriers to adequate service delivery. For physical activity services, insufficient financial resources (41.7\%) and staffing (35.4\%) and a lack of specific physical activity service specifications (25.0\%) were the main barriers. Practitioners identified inadequate staffing as the main barrier to service delivery for nutrition (42.3\%) and physical activity (23.3\%). Ideally, managers said they required $152 \%$ more specialist nutritionists in the workforce and $131 \%$ specialists for physical activity services to meet health outcomes in addition to other generalist staff.

Conclusion: Human and financial resources and organisational factors were the main barriers to meeting obesity, and public health nutrition and physical activity outcomes. Services were being delivered by generalists rather than specialists, which may reduce service effectiveness. Although conclusions from this research need to take into account the fact that the audit was conducted in 2004, the findings suggest that there was a need to equip health services with an adequately skilled workforce of sufficient capacity to deliver an effective public health response to the obesity epidemic, particularly addressing poor nutrition and physical inactivity.
\end{abstract}

Keywords: Workforce, Nutrition, Physical activity, Capacity

Abbreviations: FTE, Full-time equivalents; NAPA, Nutrition and physical activity; NHPA, National Health Priority Areas; NPAB, Nutrition and physical activity Branch; PA, Physical Activity; PHN, Public Health Nutrition; WA, Western Australia

\footnotetext{
* Correspondence: a.begley@curtin.edu.au

${ }^{1}$ School of Public Health, Curtin University, Kent Street, GPO Box U1987, Perth

6845, WA, Australia

Full list of author information is available at the end of the article
}

\section{Ciomed Central}

(c) 2016 The Author(s). Open Access This article is distributed under the terms of the Creative Commons Attribution 4.0 International License (http://creativecommons.org/licenses/by/4.0/, which permits unrestricted use, distribution, and reproduction in any medium, provided you give appropriate credit to the original author(s) and the source, provide a link to the Creative Commons license, and indicate if changes were made. The Creative Commons Public Domain Dedication waiver (http://creativecommons.org/publicdomain/zero/1.0/) applies to the data made available in this article, unless otherwise stated. 


\section{Background}

The increasing prevalence of obesity and noncommunicable chronic disease in Australia requires a range of actions and interventions to enable effective prevention policy and programs [1]. The health and economic costs of poor nutrition and physical inactivity contributing to obesity are greater than that of smoking and harmful and hazardous alcohol consumption [2]. Healthy eating and regular physical activity at any age can substantially protect against weight gain, obesity and diet-related chronic illness, and therefore reduce preventable chronic disease and associated healthcare costs [3]. It is acknowledged that public health services designed to improve NAPA are essential to reduce the increasing prevalence of chronic disease [4].

Effective interventions require sufficiently sized and skilled workforce to achieve prevention targets [5]. An appropriately trained workforce to implement healthy eating and physical activity disease prevention strategies is a priority public health infrastructure needed to impact on rising obesity rates [6]. It is not easy to quantify the size of the workforce required but there is no doubt that an appropriate workforce will have a profound impact on the ability to achieve effective outcomes [7]. A critical mass in workforce is required for effective service delivery [8]. To foster workforce adequacy there is a need to firstly consider workforce development through appropriate training and curriculum and secondly to consider the existing workforce capacity to design and deliver effective obesity prevention programs including planning considerations to address future challenges.

Australian public health policy asserted that a range of professionals in public and primary health are required to support population and community based activities and indicated that public health nutritionists and health promotion officers specializing in physical activity are important health professionals to deliver these services [1]. Research suggests that the prevention workforce in other countries is lacking practitioners with specific skills and responsibility for effective public health NAPA action [9, 10]. Little is known about Australia's obesity prevention workforce or the public health workforce more broadly. However, there has been concern since 2009 that the level of capacity in the specialist obesity prevention workforce is lacking in most jurisdictions including local government, state government and non-government organisations across Australia [1]. It is likely that the promotion of healthy eating and physical activity is relegated to general staff with lack of additional resources and variable levels of training and/or there is a lack of service delivery. The lack of workforce capacity has been identified as the result of several factors including a lack of specific workforce development efforts and workforce effectiveness associated with population health outcomes [11].
Public health nutrition is a discipline defined as the promotion and maintenance of nutrition-related health and wellbeing of populations through organised efforts and informed choices of society [12, 13]. Workforce development is a key strategic domain for building capacity for public health nutrition practice therefore it has been necessary to define the role and scope of the workforce and the competencies required [9, 14-16]. There is international agreement that whilst public health work is multi-sectorial and multidisciplinary, the most effective programs to achieve public health nutrition goals are those facilitated by a specialist workforce identified by specific competencies [17]. Australia's 10 year national agenda for action for public health nutrition, Eat Well Australia 2001-10, provided the mandate for capacity building priorities to consider workforce development as a central strategy [18].

Global efforts for public health action in physical activity have also recognised the opportunistic nature of past workforce development and the recurrent need for systematic workforce development [19]. The International Society for Physical Activity and Health was formed in 2009 with a view to moving physical activity to mainstream public health services [20]. The physical activity workforce broadly includes practitioners from health, education, sport and recreation, planning, transport and other disciplines such as medicine [21]. Whilst the broad range of sectors involved can be mobilised to engage in physical activity promotion, the variability in knowledge, skills and training may hinder population based program development efforts. The range of programs provided include examples such as the medicalisation of physical activity risk to exercise physiology where athletic performance is the target, or physiotherapists with rehabilitation as their target [21]. The public health physical activity workforce is emerging with specific positions created, however, there is an imperative to develop a physical activity promotion workforce across a range of disciplines [22].

Little is known about the priority placed on NAPA public health programs or the workforce size needed to support effective efforts to build workforce capacity [23]. As the policy environment continues to focus on reducing obesity in Australia there is an urgent need to profile the obesity prevention workforce. The composition, practice methods, resource allocation and organisation issues are all likely to impact on workforce capacity to address obesity. An audit of the NAPA workforce was carried out in Western Australia in 2004 to explore the policy environment and future workforce needs. This audit was commissioned by the Nutrition and Physical Activity Branch (NPAB) of the Department of Health in Western Australia. The Western Australian Health Promotion Foundation (Healthway) funded Curtin 
University's Food Law, Policy and Communications to Improve Public Health Research Translation Project to enable results to be published. The specific objectives of the audit were to describe the current priorities for NAPA and workforce structure of the WA NAPA workforce, as determined by health managers and practitioners. This paper reports on the 2004 workforce audit to determine the appropriateness of priorities and size of the workforce to meet the challenges of addressing obesity prevention as an important function of workforce capacity. These results are significant as they are the only workforce data for both workforce areas to be published for Australia and the findings enable the retrospective exploration of factors impacting on workforce capacity and development in relation to policy directives so as to inform future strategies.

\section{Methods}

NAPA services were defined for the purposes of the audit as any service offered in the form of education, program delivery, community or policy development that seeks to improve the food intake and physical activity levels of specific target groups or the population in general. The audit consisted of two surveys; the first was a telephone survey of managers of the obesity prevention workforce in NAPA services and the second a postal survey of the existing workforce (practitioners).

\section{Workforce definitions}

To describe the current workforce it was necessary to elucidate the types of workforce, with a variety of qualifications currently employed in obesity prevention. Workforce definitions describing different paradigms in the nutrition workforce were used as the basis to describe key workforce areas for consideration. Workforce positions in public health nutrition, community nutrition or dietetics and clinical dietetics formed the specialist nutrition workforce. In Australia, people working in these positions would have Bachelor and/or postgraduate university nutrition and/or dietetics qualifications. It is expected that other professionals working in health, such as health promotion officers and Aboriginal health workers, would also have some role in the delivery of nutrition services. This workforce may have little or no training in nutrition but be experts in other areas, for example health promotion program delivery. For the purpose of this audit this section of the workforce is described as the generalist nutrition workforce. Detailed descriptions of the specialist and generalist nutrition workforce to represent a spectrum of workforce, as adapted from Hughes and Somerset (1997) [24]. These descriptions were then applied to definitions of the physical activity workforce as no previous literature had identified a taxonomy for defining that workforce at the time of the survey.
Definitions of delineated service delivery describing the different features of methods and processes were also adapted and defined for the purpose of the study [8]. Community and Public Health delivery are usually differentiated by intended reach, prevention level, and the wellness/or illness paradigm for operation in Australia [24]. One way to consider workforce was to differentiate between the multiple workforce tiers by the determinant driving the service delivery. Determinants such as community development, needs assessment and policy directives indicate that different workforce competencies are required for community and public health NAPA approaches.

\section{Questionnaire development}

Separate manager and practitioner surveys were developed to measure the research objectives based on previous survey's including an unpublished state government Review of Allied Health Professionals Recruitment and Retention Taskforce Survey (1999), the Dietitians Association of Australia's professional competencies [25], general health promotion competencies [26] and a public health nutrition workforce development study [27]. Questions selected aimed to measure priority placed on NAPA services based on required service reporting areas and were mostly closed ended. The Department of Health required service reporting areas and potential national health priority and target areas were listed and managers could select those applicable. Other questions required the enumeration of specialist and generalist workforce and perceptions of current workforce in relation to adequacy, competency and training needs and perceived ability to meet NAPA service goals. A workforce profiling was conducted using the position title, fractional appointment and location of specialist and generalist workforce and description of services provided. Current workforce and future workforce requirements were then calculated for each region and totalled for the state.

The practitioner postage survey included the questions described above with additional details on years working in their current position, methods of training and continuing professional development and perceived barriers to service delivery. Both questionnaires were developed in conjunction with NPAB staff for content validity and were piloted on university staff for comprehensibility and face validity. Ethics approval was granted from Curtin University's Human Research Ethics Committee. All participants signed consent to participate and data was anonymised and aggregated for regions and then the state. Confidentially was maintained at all times and all participants consented to the publication of the results in various formats for the Department of Health's purposes. 


\section{Recruitment}

Western Australia is a geographically large state $(2,532,400$ square kilometres) with a population in 2004 estimated to be just under 2 million [28]. There were four metropolitan government health regions including public and community health, seven regional public and community health units and several non-government organisations and welfare organisations involved in prevention service delivery at the time of the survey. Fifteen medical general practices were also organised in geographic areas across the state with a mandate for promoting NAPA [29]. Managers were defined as a person who directly or indirectly line managed practitioner/s that have a functional responsibility to deliver nutrition and/or physical activity services for an area/region or organisation in community, public and population health. The term 'services' was used to broadly cover interventions and strategies designed to improve the risk factors of interest (public health NAPA). During the audit several revisions were made to the recruitment list due to restructuring and people on leave or acting in positions, with 69 managers identified by the end of the survey period. An email was sent to managers with an introductory letter explaining the aim of the audit including research consent and a copy of the questionnaire and workforce descriptions. Managers were asked to respond with details of their current NAPA workforce and a telephone interview was arranged to complete the questionnaire and elicit other comments regarding the workforce. A \$20 gift voucher was sent at the completion of the interviews as an incentive to encourage a high response rate. Manager's interviews were carried out over 3 months and lasted between 30 and $60 \mathrm{~min}$. All interviews were carried out by the primary author.

Practitioners were defined as a person who delivers nutrition and/or physical activity services as part of their employment. Practitioners were identified from contact lists of the NPAB and professional organisation mailing lists. As well as the original lists, a snowball approach was used to identify additional practitioners by asking survey participants to nominate other specialist or generalist practitioners. All 185 practitioners identified at the start of the survey were mailed an introductory letter, research consent form and questionnaire with replied paid envelope. They were also asked to send a copy of their job description form outlining organisational structure, key duties and competencies required for the position.

\section{Analysis}

Responses to closed-ended questions were coded directly onto the questionnaire and responses to openended questions were summarised and then coded according to a pre-established coding protocol developed after the interviews. Both sets of questionnaires were analysed using SPSS version 11 (SPSS Inc., Chicago, IL, USA), using descriptive statistics and chi-square test of association to assess relationships between data.

\section{Results}

Forty eight managers were interviewed (a $70 \%$ response rate) and 101 of the 185 practitioners identified participated (a $56 \%$ responses rate). The representative spread across all WA health regions and organisations enabled enumeration of the current NAPA workforce.

\section{Demographic characteristics}

Over half of the managers $(55.8 \%)$ had been in their current position for 2 years or less. Their main service delivery was in population services $(37.5 \%)$, community and clinical (29\%), solely community (25\%), public health $(6.3 \%)$ and clinical only $(2.1 \%)$. The majority of managers $(62.5 \%)$ were located in country areas with $87.5 \%$ having regional service delivery. There was variability in the highest qualification held, with only $10.4 \%$ having attained a Master of Public Health qualification.

NAPA practitioners were mostly female $(97 \%)$ with a mean age of 36.5 years. Most (90\%) delivered nutrition services and $54.5 \%$ delivered physical activity services. The nutrition workforce was more experienced, $41 \%$ had over 10 years' experience compared to $8.9 \%$ of the physical activity practitioners. Most practitioners (76.2 \%) had nutrition and/or dietetic qualifications, $4.9 \%$ had health promotion qualifications and $13.8 \%$ had diabetes educator qualifications. The main employers were the Department of Health (70.3 \%) and nongovernment organisations $(9.9 \%)$ and the remainder from private business. Two thirds $(65.4 \%)$ of practitioners were employed in the metropolitan area reflecting the population distribution.

\section{Services and health priority}

All managers had some responsibility for nutrition and/ or physical activity service delivery. Table 1 shows that managers rated NAPA services as priority service delivery areas along with many other competing priorities, particularly in regional areas where alcohol and other drugs and injury prevention (including assault \& suicide) were rated higher. Diabetes (35.4\%), reducing harm from alcohol and other drugs (33.3\%), cardiovascular disease $(27.1 \%)$ and injury prevention $(25 \%)$ were the priority health risks. As key risk factors for chronic disease, poor nutrition was ranked 11th and inadequate physical activity 13 th in priorities.

The health issues reflected in the ranking of the top five intervention strategies used by managers for their region or organisation. Eight key interventions were predetermined based on expected Department of Health service reporting and the top five listed by managers 
Table 1 Managers self-reported major health issues for their regions/organisations $(n=48)$

\begin{tabular}{lc}
\hline Major Health Issue & $\%(n=48)$ \\
\hline Diabetes & 35.4 \\
Drugs \& Alcohol & 33.3 \\
Cardiovascular Disease & 27.1 \\
Injury, Assault, Suicide & 25.0 \\
National Health Priority Areas ${ }^{\mathrm{a}}$ & 22.9 \\
Mental Health & 20.1 \\
Maternal and Child Health & 20.1 \\
Social Impacts/Socioeconomic Status & 18.8 \\
Obesity & 18.8 \\
Indigenous Health & 16.6 \\
Poor Nutrition & 14.6 \\
Lifestyle Risk Factors & 12.5 \\
Inadequate Physical Activity & 10.4 \\
Smoking & 10.4 \\
Cancer & 8.3 \\
Asthma & 8.3 \\
Renal & 6.2 \\
\hline
\end{tabular}

${ }^{a}$ Australia's seven national health priority areas recognised by government in 2004 as Cardiovascular Health, Cancer Control, Diabetes Mellitus, Injury Prevention and Control, Mental Health, Arthritis and Musculoskeletal Conditions; Asthma (http://www.aihw.gov.au/national-health-priority-areas/)

were improving physical activity (75\%); improving nutrition (70.8 \%); capacity building (68.7\%); reducing drugs and alcohol (68.7 \%) and addressing obesity (62.5\%). Indigenous people were key target areas identified by three quarters of managers for NAPA services. The second key target areas for managers were women and children however the focus for practitioners were adults in general for both areas of service delivery.

\section{Size and type of NAPA workforce}

One quarter of managers had no direct management of positions that were involved in physical activity service delivery and $10 \%$ had no direct responsibility for staff delivering nutrition services. Table 2 shows the 18 different job titles identified as delivering nutrition services. The total specialist nutrition workforce was estimated to be 53.1 full time equivalents (FTE) state-wide or $9 \%$ of the total workforce with the majority having a dietetic qualification as reflected by job descriptions. Practitioners who identified with community delivery roles also had position descriptions that required delivering clinical services (35\%). The majority of managers' capacity to deliver nutrition services fell to a generalist workforce of Aboriginal health workers and community nurses without explicit public health or community nutrition skills in their job descriptions (528.8FTE in total).
The majority of physical activity services were delivered by health promotion officers, community physiotherapists, nurses and/or Aboriginal health workers in a preventive role (see Table 2). The specialist workforce was estimated at 47.5 FTE or $14 \%$ of the total physical activity workforce, and the general physical activity workforce was estimated to be 335.1 FTE.

\section{NAPA service delivery}

Managers and practitioners were in agreement about the achievement of service delivery against policy goals or strategic plan objectives. Few managers $(4.3 \%)$ and practitioners $(5.9 \%)$ thought that physical activity goals were being met (\%) while $10.4 \%$ of managers and $9.0 \%$ of practitioners indicated nutrition goals were being met. Implications of not meeting goals including the recognition that services were stretched, and the limited ability to use capacity building or community development approaches to respond to the issues and lack of ability to service disadvantaged groups. The major barriers to full nutrition service delivery identified by managers was a lack of staff $(60.4 \%)$, organisational and management factors (39.5\%) and financial resources $(30.2 \%)$. The major barriers for full physical activity service delivery were financial (41.7 \%), lack of staff $(35.4 \%)$ and physical activity not being clearly identified in service specifications $(25.0 \%)$.

Recruitment and retention of staff to deliver nutrition services were barriers to service delivery reported by managers, particularly in relation to attracting staff to regional areas $(20.8 \%)$ and staff burn out $(10.4 \%)$. Lack of funding (14.5\%) and the limited number of dietetics trained professionals applying for public health nutrition (PHN) positions (14.5\%) were also considered barriers to delivering nutrition services. There were similar issues to the recruitment and retention of staff to deliver physical activity services, however physical activity was viewed by some managers $(10.4 \%)$ as being a newer or untested area for service delivery.

\section{Future workforce requirements}

Three quarters of managers said more staff were needed to fully deliver on nutrition service goals, particularly from specialist workforce. An additional 81FTE of specialist workforce (152\% more) and 62FTE (12\% more) of generalist workforce such as health promotion officers was identified as necessary which included filling currently vacant positions. Ideally, the additional specialist workforce would be dietitians (45\%), health promotion officers (17 \%), and public health nutritionists (13\%). Figure 1 illustrates the comparison between the current workforce and the estimated additional specialist workforce required by managers to fully deliver on nutrition service goals. 
Table 2 Types of Positions Responsible for Delivering NAPA Services under direct supervision by Managers (FTE))

\begin{tabular}{|c|c|c|c|c|}
\hline Type & Job Description & $\begin{array}{l}\% \\
(n=43)\end{array}$ & FTE & $\begin{array}{l}\text { \% FTE of Total } \\
\text { Nutrition } \\
\text { Workforce }\end{array}$ \\
\hline \multirow[t]{8}{*}{$\begin{array}{l}\text { Specialist } \\
\text { Workforce }\end{array}$} & $\begin{array}{l}\text { Community/Clinical } \\
\text { Dietitians }\end{array}$ & 32.6 & 18.4 & \multirow[t]{8}{*}{$8 \%$} \\
\hline & $\begin{array}{l}\text { Community } \\
\text { Dietitians }\end{array}$ & 20.9 & 13.9 & \\
\hline & $\begin{array}{l}\text { Public Health } \\
\text { Nutritionist }\end{array}$ & 16.3 & 6.2 & \\
\hline & Clinical Dietitians & 7.0 & 2.5 & \\
\hline & $\begin{array}{l}\text { Nutrition } \\
\text { Co-ordinators }\end{array}$ & 9.3 & 4.0 & \\
\hline & $\begin{array}{l}\text { Population Health } \\
\text { Nutritionist }\end{array}$ & 2.3 & 1.0 & \\
\hline & $\begin{array}{l}\text { Community } \\
\text { Nutritionist }\end{array}$ & 0 & 0 & \\
\hline & $\begin{array}{l}\text { TOTAL } \\
\text { Specialist FTE }\end{array}$ & & $\begin{array}{l}46.0 \\
\text { FTE }\end{array}$ & \\
\hline \multirow[t]{13}{*}{$\begin{array}{l}\text { Generalist } \\
\text { Workforce }\end{array}$} & $\begin{array}{l}\text { Aboriginal Health } \\
\text { Workers }\end{array}$ & 62.7 & 88.0 & \multirow[t]{15}{*}{$92 \%$} \\
\hline & Nurses & 48.8 & 371.0 & \\
\hline & $\begin{array}{l}\text { Health Promotion } \\
\text { Officers/Project } \\
\text { Officers }\end{array}$ & 44.0 & 25.0 & \\
\hline & Diabetes Educators & 46.5 & 21.2 & \\
\hline & Project Officers & 13.9 & 12.0 & \\
\hline & CVD Coordinators & 4.6 & 2.0 & \\
\hline & $\begin{array}{l}\text { Chronic Disease } \\
\text { Co-ordinators }\end{array}$ & 4.6 & 2.0 & \\
\hline & $\begin{array}{l}\text { Health Advancement } \\
\text { Officers }\end{array}$ & 2.3 & 0.6 & \\
\hline & Research Officers & 2.3 & 1.0 & \\
\hline & $\begin{array}{l}\text { Secondary Prevention } \\
\text { manager }\end{array}$ & 2.3 & 1.0 & \\
\hline & $\begin{array}{l}\text { Early Intervention } \\
\text { Staff }\end{array}$ & 2.3 & 1.0 & \\
\hline & Liaison Officer & 2.3 & 1.0 & \\
\hline & TOTAL Generalist FTE & & $\begin{array}{l}525.8 \\
\text { FTE }\end{array}$ & \\
\hline $\begin{array}{l}\text { Department } \\
\text { of Health } \\
\text { Head Office }\end{array}$ & Project Officers & & 7.1 & \\
\hline \multirow[t]{2}{*}{ TOTAL FTE } & & & $\begin{array}{l}578.9 \\
\mathrm{FTE}^{\mathrm{a}}\end{array}$ & \\
\hline & Job Description & $\begin{array}{l}\%(n= \\
36)\end{array}$ & FTE & $\%$ FTE \\
\hline $\begin{array}{l}\text { Specialist } \\
\text { Physical }\end{array}$ & $\begin{array}{l}\text { Health Promotion } \\
\text { Officer }\end{array}$ & 58.3 & 43.5 & \\
\hline \multirow[t]{2}{*}{$\begin{array}{l}\text { Activity } \\
\text { Workforce }\end{array}$} & $\begin{array}{l}\text { Physical Activity } \\
\text { Co-ordinators }\end{array}$ & 8.3 & 2.5 & \multirow[t]{2}{*}{$14 \%$} \\
\hline & TOTAL Specialist & & $\begin{array}{l}46.0 \\
\text { FTE }\end{array}$ & \\
\hline
\end{tabular}

Table 2 Types of Positions Responsible for Delivering NAPA Services under direct supervision by Managers (FTE)) (Continued)

\begin{tabular}{|c|c|c|c|c|}
\hline & $\begin{array}{l}\text { Community } \\
\text { Physiotherapists }\end{array}$ & 50.0 & 38.0 & \\
\hline & Nurses & 44.4 & 152.0 & \\
\hline & $\begin{array}{l}\text { Aboriginal Health } \\
\text { Workers }\end{array}$ & 36.1 & 54.0 & \\
\hline & Project Officer & 22.2 & 14.0 & $86 \%$ \\
\hline & $\begin{array}{l}\text { Chronic Disease } \\
\text { Co-ordinators }\end{array}$ & 12.5 & 8.0 & \\
\hline $\begin{array}{l}\text { Generalist } \\
\text { Physical }\end{array}$ & $\begin{array}{l}\text { Public Health } \\
\text { Nutritionists }\end{array}$ & 11.1 & 3.6 & \\
\hline \multirow[t]{9}{*}{$\begin{array}{l}\text { Activity } \\
\text { Workforce }\end{array}$} & $\begin{array}{l}\text { Community } \\
\text { Dietitians }\end{array}$ & 11.1 & 6.0 & \\
\hline & $\begin{array}{l}\text { Diabetes } \\
\text { Co-ordinator }\end{array}$ & 11.1 & 4.0 & \\
\hline & Therapy Assistant & 8.3 & 3.0 & \\
\hline & Clinical Dietitians & 5.5 & 2.0 & \\
\hline & Researcher & 5.5 & 2.0 & \\
\hline & $\begin{array}{l}\text { Occupational } \\
\text { Therapist }\end{array}$ & 2.8 & 1.0 & \\
\hline & $\begin{array}{l}\text { Population Health } \\
\text { Nutritionist }\end{array}$ & - & - & \\
\hline & $\begin{array}{l}\text { Community } \\
\text { Nutritionist }\end{array}$ & - & - & \\
\hline & TOTAL Generalist & & 287.6 & \\
\hline \multirow{2}{*}{$\begin{array}{l}\text { Department of } \\
\text { Health - Head } \\
\text { Office }\end{array}$} & $\begin{array}{l}\text { Physical activity } \\
\text { project officer }\end{array}$ & & 1.5FTE & \\
\hline & TOTAL FTE & & $\begin{array}{l}335.1 \\
\text { FTE }^{\mathrm{b}}\end{array}$ & \\
\hline
\end{tabular}

a 2 managers unable to estimate FTE

${ }^{b} 2$ managers unable to estimate FTE

In relation to full physical activity service delivery, the majority of managers said that an additional 56.6 FTE (131 \% more) of specialist physical activity workforce and 52FTE (16\% more) from generalist workforce was required including filling currently vacant positions.

\section{Discussion}

The 2004 WA nutrition and physical activity (NAPA) workforce audit described and quantified the priority and capacity for service delivery from a public health perspective. Even though NAPA are key risk factors for preventable chronic disease and obesity they were considered a low service delivery priority in 2004 . Broad policy priorities did not always reflect practice priorities, particularly in regional areas. Increasing decision makers' awareness of the health, economic and social benefits of improving NAPA appears to be warranted. Human and financial resources were identified as major weaknesses in health service delivery only $9 \%$ of positions responsible for delivering nutrition services 


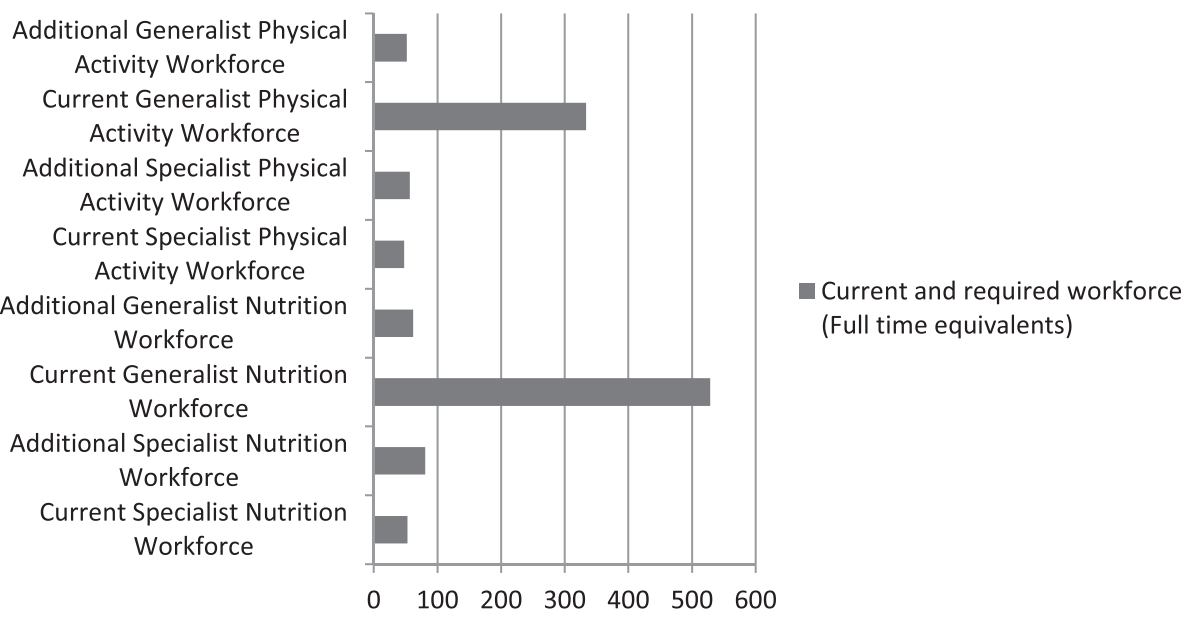

Fig. 1 Comparison between current and additional specialist and generalist NAPA workforce required to fully meet goals

occupied by suitably qualified personnel. Most managers and practitioners believed they were 'not or only partially' meeting NAPA service delivery requirements, suggesting a reduced or stretched service delivery primarily due to a lack of specialist workforce.

\section{Organisational and managerial workforce support}

Organisational and managerial support directed the services provided as well as mandated requirements by the state based Department of Health and/or other organisations. Manager's focus was on the seven chronic disease outcomes reflected in Government policy priorities at the time. The program delivery focus in WA at the time was promoting increased fruit and vegetable consumption with the Go for $2 \& 5^{\circ}$ social marketing campaign [30, 31]. In some instances other immediate local issues, for example, reducing alcohol and other drug usage were higher priorities than poor nutrition, physical inactivity or obesity. The policy priority of preventing obesity continues to increase [32], as does the need for an appropriately sized and skilled public health and primary health care workforce to deliver programs [18].

In 2004, addressing obesity was approached by encouraging employers to ensure a healthy workforce rather than building the workforce to implement actions to improve diet and physical activity [18]. Australia's public health nutrition strategic plan of action, Eat Well Australia, expressed uncertainty about whether the current workforce was large enough to undertake the tasks required to address obesity and highlighted the lack of a specific workforce development strategy [18]. The first action "Investigating workforce requirements, including training needs and the systems necessary to deliver activities in light of current funding arrangements, workforce capacity and composition" was never undertaken ([18]:26).
The policy priority assigned to specific health issues has the potential to limit service delivery. Unsupported low priority issues result in an undersized and unqualified workforce or alternatively, an undersized and underqualified workforce can influence the priority managers placed on the health issue and subsequent service delivery because they have limited capacity to act. Addressing poor nutrition is complex, there are multiple stakeholders and numerous dietary targets (e.g., increasing fruit and vegetable consumption) and approaches needed [8].

Managers' and practitioners' opinions differed in regard to meeting NAPA expectations with potential misalignment between practice and the work needed. The Indigenous population was an important target for managers yet practitioners focussed on adults in general; suggesting that disadvantaged groups, with great health need could be left out of service delivery.

\section{Workforce profiling}

A specialist workforce is critical to obesity prevention program success [18]. Findings showed an urgent need to increase the size of the specialist NAPA workforce in WA to develop the critical mass of human resources required. Managers estimated $152 \%$ more specialist nutrition and $131 \%$ more specialist physical activity workforce was required to achieve policy/program goals. The findings are consistent with research in California which found $70 \%$ of local public health department managers rated their staff capacity for obesity prevention in NAPA environments as less than effective [33].

Benchmarking the recommendations for staffing public health in NAPA areas is limited. The type of workforce is dependent on the size, training, experience and work to be achieved in the target population or the socioecological interventions needed. Just prior to the audit, 
Australian advanced level public health nutritionists were estimated as a specialist workforce capacity at $20 \%$ of that required [14], estimating that WA needed to increase to 265FTE. The only other published figures from the United States (US) planning models for workforce enumeration for government funded programs set the US ratio of 1FTE public health nutritionist to 133000 head of population in the 90s [34, 35]. Updated in 2000 by the US Association of State and Territorial Public Health Nutrition Directors to 1FTE for every 50000 head of population in consideration of the complexity of addressing obesity and nutrition of vulnerable population groups [36, 37].

Australian nutrition workforce enumeration demonstrates variability amongst states. Figures from South Australia suggested that the ratio for dedicated community nutrition positions was between 1.04 and 1.69 per 100000 people in 2003, and the Queensland specialist workforce rose to 4.8FTE per 100000 in 2003-4 and to 137.3FTE in total in 2009 [38]. WA's 2004 population was 1,982,204 with 53.1FTE specialist nutritionists [28]. Matching Queensland's investment, an additional 95.2 FTE would be required, similar to the 134.1 FTE (current and required) indicated by WA managers to fully deliver on nutrition service goals. The exemplar Queensland workforce was disbanded in 2012 following a newly elected State Government restructure which resulted in the devolution of public health with a $90 \%$ reduction to 14 FTE in total [38].

Physical activity workforce human resource requirements are more challenging to estimate as there are no clear professional recommendations. The mixture of health promotion, physiotherapy, and nursing-trained practitioners highlights the need to develop a specialist workforce by defining both the competencies and numeration requirements to contribute to effective physical activity program delivery [11].

Consistent with the 2008 National Preventive Health Taskforce recommendation to expand the supply and support training of relevant primary health workers, health promotion workers, nutritionists, and dietitians, the findings suggests an obvious way to increase workforce capacity is to invest in workforce growth [1]. In Victoria, developing workforce capacity including the FTE, benefited obesity prevention strategies [39]. The variety of position titles and selection criteria used to recruit workers may lead to variability in the WA workforce. Whilst there has been growth in dietetics as a profession this has predominantly been in clinical services [40]. The WA NAPA workforce has not grown substantially since 2004, a worrying implication for achieving obesity targets.

The importance of a diverse generalist workforce for service delivery was demonstrated but there were skill deficits in the respective areas. Reliance on the generalist workforce with limited or no training in NAPA to deliver interventions is likely to be problematic. Existing WA programs required dietetic input, e.g., FoodCents ${ }^{\circ}$ [41] and future interventions needed to address the obesogenic environment require a coordinated and skilled workforce. Whilst it is important to work in a multidisciplinary and intersectorial way to reach the whole population, a lack of training and specialist workforce to deliver targeted workforce training is also a problem.

These challenges are not confined to the Australian workforce. The US identified a lack of understanding of the complexity of the dietary change process by other practitioners and managers, lack of resources, training and mentoring to do the work, job insecurity and expectations that nutritionists would assume a variety of other roles [34, 42, 43]. Several European countries identify major constraining factors to public health nutrition workforce development [44]. Variable expectations about work roles and differences in priority placed on NAPA by managers may be due to their own preferences and/ or past work experience. Many managers were clinically trained in disciplines such as nursing, suggesting that practitioners were reporting to managers without NAPA qualifications or delivery of community public health interventions. Other workforce development issues were the impending shortage of experienced workers as many are approaching retirement age, the overall staff and the workforce instability due to high turnover or unfilled positions. Short term funding, the high proportion of female staff and dissatisfaction with career pathways were reasons identified. Interruptions to service delivery, loss of partnerships, and loss of experience when staff leave without positions being filled are priority workforce issues [8]. Professional isolation is a challenge in rural areas [43] and the with ability to work effectively with peers due to competing pressures or risk factors were identified in this study.

\section{Policy implications for building workforce capacity}

Obesity prevention requires a strategic approach to workforce planning within governments and organisations. An appropriately trained and skilled workforce can help improve diet quality and physical activity to reduce obesity and improve population health [45]. Policy level support, organisational level workforce management, and continued competency and capacity building in the existing workforce are required. Workforce development is often not part of the range of policy options for public health nutrition [46]. Although human resource capacity and training were identified in strategic Australian policy as essential to build capacity to achieve Australian obesity outcomes the policies have since been rescinded and not replaced. The chronic disease or obesity prevention emphasis rather than the direct focus on addressing poor nutrition and physical inactivity may 
contribute to this. Governments are focussing on educating the individual rather than environmental, organisational, policy and legislative and economic approaches [47]. Efforts to reduce budget expenditure such as moving to contract, part-time or generalist practitioners or less experienced practitioners also have a negative impact on overall service delivery [34].

Although there is now a mandate for implementing a workforce development strategy [48], amid growing concern about the lack and potential loss of NAPA workforce capacity, there have been no subsequent workforce audits. More research also is required on how best to train and maintain a NAPA workforce to meet current challenges and future needs.

\section{Limitations of the research}

The survey was conducted over 10 years ago and a follow-up survey is timely and urgently needed. Caution should be taken when interpreting the results of this workforce audit as the interventions delivered by the Department of Health in Western Australia at the time of the audit were largely directed by national health priority areas. This study findings show that manager's recognition of nutrition and physical activity as major health issues was a lower priority than other factors such as obesity, social impacts and mental health, see Table 1 , which may have changed since the audit. Obesity remains a public health priority and research into effective public health policy options interventions has progressed [49, 50] and emphasise the need for intersectoral action and approaches. For example, there is increasing recognition of mental health issues and stigma related to body weight [51, 52]. Further government workforce audits are recommended and would need to consider the current policy and intervention context and the broader workforce involved in prevention.

However, the findings maybe valuable for future workforce development given the lack of evidence on NAPA workforce in Australia and may contribute to evidence on the lack of progress in addressing issues such as obesity presently. The sampling was designed to target all NAPA service providers however individual practitioners in other settings who may have been involved with promotion in their clinical roles may not have been captured. The relatively low response rate among practitioners compared to managers is a limitation, however, other workforce audits have reported rates as less than $50 \%$ percent [38]. The use of snowball sampling and the uniqueness of the WA context may limit the generalisability of findings. In addition, it should be noted that the practitioner survey relied on self-report data. Also several managers were unable to estimate some of their generalist workforce's time dedicated to nutrition and or physical activity service delivery. Variable size of organisations meant some had more managers and practitioners included, although this was taken into account when enumerating the workforce so that positions were only counted once. The Department of Health NPAB manager (secondary author) who commissioned the audit was not included in the survey but the workforce at the NPAB has been included in enumeration estimates.

\section{Conclusion}

Workforce development needs to be a key strategic determinant for obesity prevention. The 2004 WA NAPA workforce audit highlighted a lack of responsibility for workforce development, an unclear and fragmented strategy, and a lack of fit for purpose workforce to deliver interventions. There is no doubt the programs required to effectively influence NAPA are challenging and complex yet there is little evidence of workforce considerations.

\section{Funding}

The Department of Health in Western Australia funded the 2003-2004 Western Australian Audit of NAPA and Healthway, the Health Promotion Foundation, funded Curtin University to assist the translation of research into practice through the "Food Law, Policy and Communications to Improve Public Health Project". http://foodpolicy.org.au/.

\section{Availability of data and materials}

The data that support the findings of this study are available from Department of Health, Western Australia but restrictions apply to the availability of these data, which were used under license for the current study, and so are not publicly available. Data are however available from the authors upon reasonable request and with permission of Department of Health, Western Australia.

\section{Authors' contributions}

$A B$ designed the study instruments and conducted the data collection and carried out the collation of information and contributed extensively to drafting and reviewing the manuscript. CP conceptualized and designed the study and assisted with the development of the instruments, and conceptualizing and drafting the manuscript, and edited and approved the final manuscript as submitted. Both authors read and approved the final manuscript.

\section{Authors' information}

$A B$ is currently a Senior Lecturer and the Course Coordinator for the Master of Dietetics at Curtin University. She has been at Curtin as a permanent staff member since 1996 is a highly experienced lecturer winning teaching awards. She is responsible for teaching the public health nutrition content for a variety of courses. Her research interests are in food literacy capabilities and effective programs, nutrition during the lifecycle and food and nutrition policy. In 2012 she was awarded Fellow of the Public Health Association of Australia in recognition of significant contribution to PHAA and the field of public health. In 2014 the Dietitians Association of Australia recognised AB as an Advanced Accredited Practicing Dietitian in recognition of leadership, education, supervision, teaching and health professional training

CP works part-time for Curtin University and the Western Australian Department of Health to try to build the capacity for nutrition epidemiology in Western Australia to inform policy and practice. CP is best known for managing the Go for $2 \& 5^{\circledR}$ fruit and vegetable social marketing campaign. She has been awarded the International Fellow of the World Cancer Research Fund, bestowed September 2012, and has achieved Fellowship of the Public Health Association of Australia, appointed September 2012. CP has a particular interest in improving nutrition for population groups who are vulnerable to poor nutrition due to their social, environmental or economic circumstances. CP was manager of the former state-wide Nutrition and Physical Activity Branch of the Department of Health at the time of the survey. 


\section{Competing interests}

The authors declare that they have no competing interests.

\section{Consent for publication}

Aggregated results from individuals are presented and no one individual can be identified. Research Information Sheets indicated the intended use of the results for reports and publications.

\section{Ethics approval and consent to participate}

Human Research Ethics approval was obtained from Curtin University's Human Research Ethics Committee Protocol Approval HR 180/2003 Part 1 and Part 2. All participants were required to provide written consent for their participation.

\section{Author details}

'School of Public Health, Curtin University, Kent Street, GPO Box U1987, Perth 6845, WA, Australia. ${ }^{2}$ Department of Health in Western Australia, 189 Royal Street, East Perth 6004, WA, Australia.

Received: 31 August 2015 Accepted: 18 August 2016

Published online: 25 August 2016

\section{References}

1. National Health Preventative Taskforce. National Preventative Health Strategy, Obesity in Australia- a need for urgent action. In: Technical Paper. Canberra: Commonwealth Department of Health and Aging; 2009.

2. Institute for Health Metrics and Evaluation. Global Burden of Disease: Australia. In: Global Burden of Diseases, Injuries and Risk Factors Study 2010. volume 2014. Seattle: Institute for Health Metrics and Evaluation; 2014. http://www.healthdata.org/australia.

3. National Health and Medical Research Council. Australian Dietary Guidelines In: National Health and Medical Research Council, vol. Commonwealth of Australia, Canberra; 2013.

4. Bodenheimer T, Chen $\mathrm{E}$, Bennett $\mathrm{H}$. Confronting the growing burden of chronic disease: Can the U.S. Health Care Workforce do the job? Health Affairs. 2009:28:64-74.

5. Gortmaker S, Swinburn BA, Levy D, Carter R, Mabry P, Finegood D, Huang T, Marsh T, Moodie M. Changing the future of obesity: science, policy and action. The Lancet. 2011;378:838-47.

6. Kugelberg S. Public health nutrition in Europe: Workforce development and policy change. Stockholm: Karolinska Institutet; 2013. https://openarchive.ki. se/xmlui/handle/10616/41338?locale-attribute=sv.

7. Swinburn B, Gill T, Kumanyika S. Obesity prevention: a proposed framework for translating evidence into action. Obesity Rev. 2005;6:23-33.

8. Hughes R. A socio-ecological analysis of the determinants of national public health nutrition workforce capacity: Australia as a case study. Fam Community Health. 2006;29:55-67.

9. Jonsdottir S, Thorsdottir I, Kugelberg S, Yngve A, Kennedy N, Hughes R. Core functions for the public health nutrition workforce in Europe: a consensus study. Public Health Nutr. 2012;15:1999-2004.

10. Yancey A, Fielding J, Flores G, Sallis J, McCarthy W, Breslow L. Creating a robust public helth infrastructure for physical activity promotion. Am J Prev Med. 2007;32:68-78.

11. Beck AJ, Boulton ML. Building an effective workforce: a systematic review of public health workforce literature. Am J Prev Med. 2012;42:S6-16.

12. World Public Health Nutrition Association. Public Health Nutrition Definition. 2007.

13. Serra-Majem L. Moving forward in public health nutrition- the 1st World Congress of Public Health Nutrition-Introduction. Nutr Rev. 2009;67:s2-6.

14. Hughes R. Public health nutrition workforce composition, core functions, competencies and capacity: perspectives of advanced-level practitioners in Australia. Public Health Nutr. 2003;6:607-13.

15. Hughes R, Begley A, Yeatman H. Aspirational competency expectations for public health nutritionists in Australia: a consensus study. Nutr Diet. 2015;72: 122-131.

16. Jonsdottir S, Hughes R, Thorsdottir I, Yngve A. Consensus on the competencies required for public health nutrition workforce development in Europe - the JobNut project. Public Health Nutr. 2011;14:1439-49.

17. Hughes R. Competencies for effective public health nutrition practice: a developing consensus. Public Health Nutr. 2003;7:683-93.
18. Strategic Intergovernmental Nutrition Alliance. Eat Well Australia: An agenda for action for public health nutrition 2000-2010. Department Health and Aged Care: Canberra; 2001.

19. Blanchard C, Shilton T, Bull F. Global Advocacy for Physical Activity (GAPA): global leadership towards a raised profile. Glob Health Promot. 2013;20:113-21.

20. Kohl H, Craig C, Lambert E, Inoue S, Alkandari JR, Leetongin G, Kahlmeier S, Group. TLPASW. The pandemic of physical inactivity: a global action for public health. The Lancet. 2012;380:294-305.

21. Shilton T. Advocacy for physical activity- from evidence to influence. IUPHEPromot Educ. 2006;X111:118-26.

22. Giles-Corti B. People or places: What should be the target? J Sci Med Sport. 2006;9:357-66.

23. Lawrence MA, Galal O, Margetts BM, Yngve A. Building global alliances for public health nutrition training. Nutr Rev. 2009;67 Suppl 1:S66-8.

24. Hughes R, Somerset S. Definitions and conceptual frameworks for public health nutrition and community nutrition: a discussion paper. Aust J Nutr Diet. 1997;54:40-5.

25. Dietitians Association of Australia. National competency standards for entry level dietetics. Canberra; 1993.

26. Shilton T, Howat P, James R, Lower T. Final Report: Review of competencies for Australian Health Promotion. Perth: Western Australian Centre for Health Promotion Research, Curtin University and National Heart Foundation of Australia (WA Division) Perth Western Australia; 2002.

27. Hughes R. Descriptive analysis of the designated public health nutrition workforce profile, practices and workforce development needs: Western Australia. In: Australian Public Health Nutrition Workforce Project. Brisbane: Nutrition Unit Griffith University; 2001.

28. Australian Bureau of Statistics. Population by Age and Sex, Western Australia, Jun 2004. In 3235555001; 2004.

29. Harris M, Hobbs C, Davies G, Simpson S, Bernard D, Stubbs A. Implementation of a SNAP intervention in two divisions of general practice: a feasibilty study. Med J Aust. 2005:183:54-60.

30. Pollard CM, Miller MR, Daly AM, Crouchley KE, O'Donoghue KJ, Lang AJ, Binns CW. Increasing fruit and vegetable consumption: success of the Western Australian Go for 285 campaign. Public Health Nutr. 2008;11:314-20.

31. Pollard C, Lewis J, Binns C. Selecting interventions to promote fruit and vegetable consumption from policy to action, a planning framework case study in Western Australia. Aust N Z Health Policy. 2009;2009.

32. Department of Health: National chronic disease strategy. Australian Health Ministers Conference, Editor. Canberra; 2005.

33. Schwarte L, Samuels S, Boyle M, Clark S, Flores G, Prentice B. Local public health departments in California: Changing nutrition and physical activity environments for obesity prevention. J Public Health Management Prac. 2010;16:E17-28.

34. Haughton B, George A. The Public Health Nutrition workforce and its future challenges: the US experience. Public Health Nutr. 2008;11:782-91.

35. Haughton B, Story M, Keir B. Profile of public health nutrition personnel: challenges for population/system-focused roles and state-level monitoring. Am Diet Assoc. 1998;98:664-70.

36. Kaufman M, Heimendinger J, Foerster S, Carroll MA. Survey of nutritionists in state and local public health agencies. J Am Diet Assoc. 1986;86:1566-70.

37. Association of State and Territorial Public Health Nutrition Directors. Survey of the Public Health Nutrition Workforce :1999-2000. In: Nutrition Assistance Program Report Series The Office of Analysis, Nutrition and Evaluation. Virginia: United States Department of Agriculture- Food and Nutrition Service; 2003. http://www.fns.usda.gov/sites/default/files/Publichealthsurvey.pdf.

38. Vidgen $H$, Adam M, Gallegos D. Who does nutrition prevention work in Queensland? An investigation of structural and political workforce reforms. Nutr Diet. 2015. early online view. doi:10.1111/1747-0080.12239.

39. Haby M, Doherty R, Welch N, Mason V. Community-based interventions for obesity prevention: lessons learned by Australian policy-makers. BMC Res Notes. 2012:5:20.

40. Health Workforce Australia. Australia's Health Workforce Series Dietitians in Focus. Canberra: Commonwealth of Australia; 2014.

41. Foley R, Pollard C. Food Cent\$-implementing and evaluating a nutrition education project focusing on value for money. Aust N Z J Public Health. 1998:22:494-501.

42. Chapman-Novakofski K, Reicks M. Dietetics practitioners in extension: what is the current climate and future demand? J Acad Nutr Diet. 2013:113:1299-301.

43. Devine CM, Jastran M, Bisogni CA. On the front line: practice satisfactions and challenges experienced by dietetics and nutrition professionals working in community settings in New York State. J Am Diet Assoc. 2004;104:787-92. 
44. Kugelberg S, Jonsdottir S, Faxelid E, Jonsson K, Fox A, Thorsdottir I, Yngve A. Public health nutrition workforce development in seven European countries: constraining and enabling factors. Public Health Nutr. 2012;15: 1989-98.

45. Yngve A, Sjostrom M, Warm D, Margetts B, Perez Rodrigo C, Nissinen A. Effective promotion of healthy nutrition and physical activity in Europe requires skilled and competent people; European Master's Programme in Public Health Nutrition. Public Health Nutr. 1999;2:449-52.

46. Yngve A, Tseng M, Haapala I, Hodge A. A robust and knowledgeable workforce is essential for public health nutrition policy implementation. Public Health Nutr. 2012;15:1979-80.

47. Caraher M, Coveney J. Public health nutrition and food policy. Public Health Nutr. 2004;7:591-8

48. Fox A, Chenhall C, Traynor M, Scythes C, Bellman J. Public health nutrition practice in Canada. Public Health Nutr. 2008;11:773-781.

49. Swinburn B, Sacks G, Vandevijvere S, Kumanyika S, Lobstein T, Neal B, Barquera S, Friel S, Hawkes C, Kelly B, et al. INFORMAS (International Network for Food and Obesity/non-communicable diseases Research, Monitoring and Action Support): overview and key principles. Obes Rev. 2013;14 Suppl 1:1-12.

50. Hawkes C, Jewell J, Allen K. A food policy package for healthy diets and the prevention of obesity and diet-related non-communicable diseases: the NOURISHING framework. Obes Rev. 2013;14 Suppl 2:159-68.

51. Puhl RM, Heuer CA. Obesity stigma: important considerations for public health. Am J Public Health. 2010;100:1019-28.

52. Macpherson-Sanchez AE. Integrating fundamental concepts of obesity and eating disorders: implications for the obesity epidemic. Am J Public Health. 2015;105:e71-85.

\section{Submit your next manuscript to BioMed Central and we will help you at every step:}

- We accept pre-submission inquiries

- Our selector tool helps you to find the most relevant journal

- We provide round the clock customer support

- Convenient online submission

- Thorough peer review

- Inclusion in PubMed and all major indexing services

- Maximum visibility for your research

Submit your manuscript at www.biomedcentral.com/submit 